\title{
Understanding the Line Managers' HRM Role Expectations: Does Size Matter?
}

\author{
Nik Hazimah Nik Mat ${ }^{1} \&$ Rowena Barrett ${ }^{2}$ \\ ${ }^{1}$ School of Maritime Business and Management, University Malaysia Terengganu, Terengganu, Malaysia \\ ${ }^{2}$ QUT Business School, Queensland University of Technology, Brisbane, Australia \\ Correspondence: Nik Hazimah Nik Mat, School of Maritime Business and Management, University Malaysia \\ Terengganu, Terengganu, Malaysia. Tel: 60-9-668-4430. E-mail: nikhazimah@umt.edu.my
}

\author{
Received: February 2, 2015 Accepted: April 16, 2015 Online Published: June 13, 2015 \\ doi:10.5539/ass.v11n16p118 URL: http://dx.doi.org/10.5539/ass.v11n16p118
}

\begin{abstract}
Recent years have witnessed burgeoning interest in the line managers' contribution to HRM effectiveness. This effort requires organizations to consider important contextual conditions to ensure the desired organizational outcomes. This paper explores the significance of the organization size in understanding the line managers' involvement in HRM activities. Two case studies were conducted, one in a large and another in a small airport involving key members of the airport management who were closely related to the line managers' HRM role. Content analysis was employed to analyze data from the interviews and written documents. While there were many similarities in the line managers' HRM role, the differences in the line managers' HRM role expectations are also found to be related to differences in the size of the organization. More responsibility is expected from line managers in the large airport as compared to the small airport. This finding has important implications in aligning the HRM strategy and organizational outcomes through the line management contribution.
\end{abstract}

Keywords: HRM role, line managers, organizational size, strategic HRM

\section{Introduction}

\subsection{Research Problem}

Despite the mounting literature on strategic HRM and devolution of HRM activities, there is scarce research on the distribution of HRM activities to line managers (LMs) that describe and specify the LMs HRM role responsibility in an organization (Cunningham \& Hyman, 1995; Valverde, Ryan, \& Soler, 2006). Much discussion of LMs involvement has been placed in the broad context of HRM activity distribution and lacks specification on each responsibility (Valverde et al., 2006). For example, focus has been given to the issues such as the activities, their position, power relationship and influence, which tends to explore what LMs actually do instead of what they should do.

Studies explore expectations of the involvement of LMs in HRM activities rely heavily on quantitative data (Khilji \& Wang, 2006). Quantitative methods have limited ability of researchers to gain an in-depth understanding of the specification of HRM activity distribution to LMs. Reliance on quantitative data fails to provide a holistic understanding of expectations of the LMs' HRM role required by their role evaluators, which include HR specialists and the LM's supervisors. Expectations of LMs' HRM role could be explored qualitatively and would enable a detailed explanation of the underlying logic of the LMs' HRM role (Nehles, Riemsdijk, Kok, \& Looise, 2006). The clarity of work role requirements depends on the interaction between LMs and their role evaluators, and so there is a need to consider multiple sources of data to understand the required performance of the LMs' HRM role. To date little attention has been paid to what key stakeholders in the organization such as the LM's supervisors and employees expect of the LMs in their HRM role (Renwick \& MacNeil, 2002).

A better understanding of the LMs' HRM role may be obtained from key members of the organization who are closely involved with LMs' HRM role. However, the expectation may differ between organization as the organization contextual conditions influence the implementation of HRM practices in organizations (Truss, Gratton, Hope-Hailey, Stiles, \& Zaleska, 2002). This include organization size as this factor influence the HRM implementation towards organizational achievement (Kaufman, 2010; Sheehan \& Cooper, 2011; Sheppeck \& 
Militello, 2000; Teo \& Rodwell, 2007). Through two case studies, the purpose of this paper is to understand the expectations of the LMs' HRM role. The case studies are of two airports in Malaysia and the roles of LMs who manage different departments in the airports are considered. The two airports differ in size, one large international and the other a smaller domestic airport.

\subsection{LMs' HRM Role Definition}

Generally, LMs are reported to be involved in many HRM activities (Cunningham \& Hyman, 1995; Renwick, 2003). LMs' involvement is found in several HRM areas including performance appraisal, recruitment and selection, training and development, managing grievance and discipline, pay and benefit and career development. In explaining LMs' increasing involvement in these activities, it is assumed that LMs are involved in practice aspects rather than leading policy issues (Marchington \& Wilkinson, 2002).

Performance appraisal is the most common HRM activity devolved to the LM (Cunningham \& Hyman, 1995). LMs play a major role in this activity as they are responsible for assessing the need of employees' training and development through employees' performance. Nevertheless, some researchers found a weak link of LMs involvement in the performance management system because LMs were reluctant to take responsible (Gratton, Hope-Hailey, Stiles, \& Truss, 1999). Limited responsibility and uneven devolution of responsibility to LMs, contributes to the ambiguity about their role (Cunningham \& Hyman, 1995; McGovern, Gratton, Hope-Hailey, Stiles, \& Truss, 1997). Ambiguity is also seen in their uncertainty about the depth of their involvement or autonomy in undertaking performance appraisals. As a result, several organizations revealed that LMs did not perform well even though they believed they did perform well (Renwick, 2000).

Cunningham and Hyman (1995) contend that LMs are also involved in recruitment and selection. Even though decisions on recruitment and selection are often handled by HR specialist, LMs are occasionally involved in the decision making (Nehles et al., 2006). This suggests that LMs do not exert much influence over these activities.

There appears to be little research on the involvement of LMs in the training and development activity (Renwick \& MacNeil, 2002). These activities can be an extension of the performance appraisals process where the LM identifies employees' training and development needs (Cunningham \& Hyman, 1995). LMs' involvement in this HR activity enables the creation of an environment that enhances employee performance and increases their satisfaction at work (Gibb, 2003).

Increasingly LMs are involved in managing discipline but HR specialist authority has been found to outweigh the LM influence. Rollison et al.'s (1996) study found that LMs demographics (i.e. gender, age and tenure) did not significantly change the way they handle discipline issues, but gender was an issue in the management of grievances, in that female employees were handled more firmly than male employees. Moreover, the study noted that the style of managing grievance and discipline issues differed according to the issue at hand and the most serious issues were approached in the harshest way (Rollison, Hook, Foot, \& Handley, 1996, p. 50). The way LMs handle the grievance and discipline issues is affected by the limited authority they have and therefore they are likely to refer certain issues to the higher management (Rollison et al., 1996).

Currie and Procter (2001) investigated the involvement of LMs in setting pay and benefits, and suggested this varies depending on the situation. Their study was conducted at Edward Hospital Trust, a partly government owned institution and this impacted the boundaries within which decisions about pay and benefits could be determined. So for instance, when the government invoked a cost-neutral policy in determining local pay for employees, LMs had little opportunity to influence pay. However, when the organization moved towards developing a local pay framework that could solve a specific operational problem, LMs involvement was greater as they were able to initiate and influence the content of the framework. From this, Currie and Procter (2001) conclude that although LMs role tends to vary, they play an important 'link pin' role between operational and strategic level activity regardless of the situation facing the organization.

LMs involvement in career development is viewed as a shared responsibility with HR specialists (Renwick \& MacNeil, 2002). Only with HR specialists support could LMs play a role in career development activities. This is the case as many HR specialists view LMs as lacking skills to manage career development activities(Hall \& Torrington, 1998). As a result, researchers point out that HR specialists should also be responsible for poor HRM role implementation by LMs on career development as it reflects on the failure of HR specialists to fulfill their role to support and advise the LM on related matters (Renwick \& MacNeil, 2002).

\subsection{The Impact of Organizational Size on LMs' HRM Role}

Although researchers agreed that organization size is one of the contextual condition that influence the HRM implementation (Kaufman, 2010; Sheehan \& Cooper, 2011; Sheppeck \& Militello, 2000; Teo \& Rodwell, 2007), 
a minimal amount of literature was found dealing with the impact of organizational size on LMs' involvement in HRM. Most studies concentrated on the link between organizational size and strategic HRM and did not specifically explore on its impact to the development of the LMs' HRM role. For example, Sheehan and Cooper's (2011) study investigate the impact of organizational size and HRM outsourcing and found that smaller size organization was more likely to outsource their HRM activities. This finding has been associated with higher unit cost incurred by the small organizations if they provide in-house HRM services. Generally, most studies indicate differences on the HRM implementation between small and large organization but failed to provide depth of information on how the organizational size influence the expectation of the LMs HRM role.

Other researchers have discussed about the impact of organizational size in terms of different level of organizational structure namely organizational centre and periphery. In the study about the strategy creation in four multinational corporations, Regner's (2003) study found significant differences on expectations of managerial activities between organizational centre and its peripheries. Managers in the organizational peripheries were expected to involve in the inductive strategy while deductive strategy was implemented by managers in the organizational centre. This researcher referred the inductive strategy as externally oriented strategy activities of an explorative character directed at strategy creation differed with the deductive strategy which was more industry and exploitation focused actions aligned with the existing strategy (Regner, 2003, p. 58). Based on the finding, the study suggested that managers in the periphery were expected to be more flexible and explore activities that appropriate with its situations compared to managers in the organizational centre which was required to perform tasks that were routine in nature. This was believed to be contributed by the situation in both organizational structures which differed between one another. Organizational centre was regarded as more stable environment than complex situations at the organizational peripheries. This finding was parallel with other study which found that negotiations amongst LMs were believed to have a huge impact on managing activities in the absence of top management (Balogun \& Johnson, 2004).

Considering the implications of heightened LMs' HRM role in the organization, the impact of the organization size on the development of the LMs' HRM role would be an important factor to be considered for organizational competitiveness. This is due to the fact that the changing structure in organizations contributed to the increased expectations for the LMs to perform the HR function (Ulrich, Younger, Brockbank, \& Ulrich, 2012). Therefore, the identification of HRM role expectations in different organization size is more critical for LMs to understand their role and respond to the competing pressure from members in the organization. As such, each organizational size may have different work role requirement that influence how the role expectations were developed by members in the organization and delivered to LMs towards achieving the role consensus (Dierdorff \& Morgan, 2007). Changes to expectations of LMs HRM role are evident yet there is scarcity of research on its impact to the devolution of HRM activities to LMs (Budhwar, 2000). The purpose of this research is to explore how the LMs HRM role is enacted in two organizations and determine the key influence on the way their HRM role is defined. In the next section, the research methods are described before the findings of the two cases are reported and analyzed.

\section{Methodology}

Despite significant attention given by researchers to LM involvement in the HRM activities, it is apparent that exploration of this topic is limited to Western countries. It is important to focus attention on developing countries to understand HRM role development in different parts of the world. A gap in HRM literature on LMs' HRM role has been identified among important emerging countries such as Malaysia, Indonesia and Thailand (Rees \& Johari, 2010). This research will be conducted in Malaysia. Choosing Malaysia as the focus of the study may provide a different platform to enhance understanding of the LMs' HRM roles, and fill this gap in the literature.

Two airports in Malaysia that operated under the same parent company were chosen to study. A case study approach was employed to draw together information gathered in semi-structured interviews, observations and documentation. Documents including company websites, annual reports and internal company documents were analyzed to gain general and background information regarding the parent company. Interviews were carried out with nine participants, including seven Senior Managers and two HR representatives. Senior managers were those managers who were responsible for defining the LMs' HRM role, evaluating LMs' performance and influencing the way the LMs perform their HRM role. Senior managers were the heads of each unit that participated in the study. These senior managers represented the role evaluators' views of the HRM role of LMs. They were an important source of information as they directly monitored LMs' work and evaluated their performance. HR representatives were defined as those involved in managing HR related issues, particularly with regards to HRM policy and practices throughout the organization. As HR practitioners, it was assumed that they understood the HRM processes and procedures and were the referral point for LMs on issues related to 
HRM activities. Interviews focused on the LMs' HRM roles and covered their intended HRM roles. Interview questions were developed from previous studies related to LMs' involvement in HRM activities and input from discussions with senior managers and HR representative.

As well as recording the interviews, the researcher took notes and maintained a reflective diary of the interview process to assist with subsequent analysis of the transcripts. All interviews were transcribed. Since the majority of interviews were conducted in Malay, the transcribed scripts were translated into English prior to the data analysis. Content analysis of the data was undertaken to understand the expectations of the LMs' HRM role from the perspectives of those who evaluate LM's role, including heads of each unit and HR representatives. The analysis focused on the experience of unit heads and HR representatives on the LM's role in relation to HRM. The aim was to explore the process involved in the development of a role in the organizational context.

\section{Results}

The case studies were conducted in the Malaysian airport sector, which comprises 39 commercial airports operated by one parent company. The parent company was originally established as a government agency and was re-established as a private enterprise in 1992. These changes meant that the company was no longer the regulatory body responsible for the airports and aviation industry. Instead, its new focus was on three main activities at each airport: operations, management and maintenance. Airports in Malaysia cater to airlines servicing 16 domestic and 113 international destinations. The sector employs approximately 7,000 employees across the 39 airports. The airports consist of five international terminals, 16 domestic terminals and 18 short take-off and landing (STOL) ports. The airports involved for this study comprised one international airport and one domestic airport. The international airport was larger in both size and operation, having a higher capacity to accept large aircrafts and offer connectivity to other countries. The domestic airports were smaller in size and provided services for passengers within the country. They had capacity to receive smaller sized aircraft unlike the international airports.

Airport revenue came from two sources: aeronautical and non-aeronautical. Aeronautical revenue was gained from activities such as landing fees, aerobridge charges, check in-counter charges, parking fees and passenger service charges. Non-aeronautical revenue was generated from commercial activities offered to customers, including the operation of duty free shops, hotels, parking facilities and commercial space leasing. Aeronautical revenue was the major revenue stream and may influence non-aeronautical revenue. This indicated that the greater the number of aircraft that lands in an airport, then the higher the revenue. In turn, this attracted more businesses and customers to commercial activities. Thus, emphasis was given by the parent company to aeronautical revenue to ensure the quality of services provided to airlines, passengers and contractors, to generate more demand and activity at each airport.

\subsection{Airport $X$}

Airport $X$ is an international airports located in the northern region of the Malaysian Peninsular with 469 staff. It has seven functional units: four main functional units and three support units. As an international airport, Airport $\mathrm{X}$ also acts as a regional centre for four main functions including maintenance, security, fire and rescue services and finance for the northern region of the Malaysian Peninsular. The managers at this site were responsible for the operation at other airports in the region. Operating as an international airport allows Airport X to offer attractive routes to major cities around South East Asia and therefore must operate 24 hours a day. At this airport, four unit heads and one HR representative were participated in the interviews.

\subsection{Airport $Y$}

Airport $\mathrm{Y}$ is a domestic airport located in the northern region of the Malaysian Peninsular with a total of 69 employees. As a small airport, Airport Y is capable of accepting B737 aircraft and handling up to 800, 000 passengers annually. This airport supports three main functional units and one support unit: Security, Fire and Rescue Services, Operations and HR unit. At this airport, three unit heads and one HR representative were participated in the interviews.

\subsection{The HRM Activities of LMS}

The importance of gathering the experience about HRM activities is to obtain a clearer picture regarding LMs' involvement in these activities such that their HRM role can be better defined (Purcell \& Hutchinson, 2007). Instead of asking participants their opinion on a list of HRM activities decided earlier, respondents were given the opportunity to offer their thoughts on what they perceived as HRM activities which LMs should undertake in their airports. The differences in the perceived HRM activities of LMs between Airports X and Y are detailed in Table 1. As can be seen in Table 1, more activities were expected from line managers at Airport X as compared 
to Airport Y. In most of the HRM activities, line managers at Airport $Y$ assist the unit head in performing the HRM role, where needed. However, most of the processes in managing employees in the unit were completed by the unit heads.

Table 1. Differences in themes emerge regarding the involvement of LMs in HRM activities between airport X and airport $Y$

\begin{tabular}{|c|c|c|c|}
\hline \multirow{2}{*}{ No } & \multirow{2}{*}{ Themes } & \multicolumn{2}{|l|}{ Activity } \\
\hline & & Role evaluators at Airport X & Role evaluators at Airport Y \\
\hline 1. & $\begin{array}{l}\text { Performance } \\
\text { Management } \\
\text { (PMS) }\end{array}$ & $\begin{array}{l}\text { - Evaluate employee' performance } \\
\text { - Conduct meeting with employees to } \\
\text { explain their key performance indicators } \\
\text { (KPI) at the beginning of the year. } \\
\text { - Conduct performance review at mid and } \\
\text { end of the year. } \\
\text { - Justify the evaluation given to the } \\
\text { employees where necessary } \\
\text { - Complete the merit and demerit form as } \\
\text { evidence for employee' performance } \\
\text { evaluation }\end{array}$ & $\begin{array}{l}\text { - LMs are the first evaluator, the head } \\
\text { of unit (HOU) is the second } \\
\text { - Discuss together with the head of } \\
\text { unit but HOU will review it again } \\
\text { - The HOU was responsible to make a } \\
\text { decision }\end{array}$ \\
\hline 2. & Reward management & $\begin{array}{l}\text { - Remark that performance evaluation has } \\
\text { a major impact to employee rewards and it } \\
\text { justify the importance of the line } \\
\text { managers' part in employees performance } \\
\text { management } \\
\text { - Provide input and suggestion about } \\
\text { employee reward, where necessary }\end{array}$ & - None - \\
\hline 3. & $\begin{array}{l}\text { Managing attitudes and } \\
\text { discipline }\end{array}$ & $\begin{array}{l}\text { - Record employee' attendance } \\
\text { - Monitor employees' discipline } \\
\text { - Take disciplinary action if necessary } \\
\text { - Maintain proof and evidence of } \\
\text { employees' misconduct } \\
\text { - Inform the head of unit concerning any } \\
\text { serious problem of employee' discipline }\end{array}$ & $\begin{array}{l}\text { - Able to influence employees } \\
\text { attitudes through their close } \\
\text { relationship at the unit } \\
\text { - Does not responsible to decide on } \\
\text { action taken for employees } \\
\text { wrongdoing but give the report to the } \\
\text { HOU }\end{array}$ \\
\hline 4. & Work arrangement & $\begin{array}{l}\text { - Lead the shift } \\
\text { - Organise the roster and manning } \\
\text { - Ensure the number of employees are } \\
\text { sufficient in each shift } \\
\text { - Arrange for the substitute if not enough } \\
\text { employees are present } \\
\text { - Manage employee leave application } \\
\text { - Forward the leave application to the } \\
\text { head of unit } \\
\text { - Monitor overtime, sick and emergency } \\
\text { leave } \\
\text { - Administer related documentation } \\
\text { - Inform the head of unit about the } \\
\text { workforce shortage }\end{array}$ & $\begin{array}{l}\text { - Provide input that necessary for the } \\
\text { planning and manning, all related } \\
\text { processes are completed by the HOU } \\
\text { - Does not involve in planning for } \\
\text { employees' leave } \\
\text { - Follow the manning as prepared by } \\
\text { the HOU }\end{array}$ \\
\hline 5. & Training & $\begin{array}{l}\text { - Conduct roll call and training } \\
\text { - Conduct lectures and KSS } \\
\text { - Suggest any training that is necessary } \\
\text { for the unit and forward to the head of unit } \\
\text { for consideration and approval }\end{array}$ & $\begin{array}{l}\text { - Assist the HOU in any class and } \\
\text { lectures conducted by the HOU, where } \\
\text { necessary } \\
\text { - Does not involve in the planning for } \\
\text { the training } \\
\text { - Involve in the implementation part } \\
\text { (e.g. physical training, roll call) }\end{array}$ \\
\hline
\end{tabular}


In particular, two main differences were identified regarding the expectations of HRM activities for LMs: these were the number of HRM activities and their level of involvement. First, the key members of Airport X expected their LMs to be more involved in HRM activities as compared to Airport Y (refer to Table 2). All participants agreed that performance management should be implemented by the LM. This is consistent with the study by Cunningham and Hyman's (1995) findings of performance appraisal being the most common HRM activity of LMs. LMs were also expected to be involved in the attitudes and discipline management, again this is consistent with Renwick's (2003) findings on the increased involvement of LMs in this activity. There was a disagreement in rewards management activity between the two airports. Participants in Airport X believed LMs should be involved in this activity, while at Airport Y LMs HRM responsibility did not encompass this activity. Participants highlighted the administration of employee leave and management of the work roster as crucial HRM activities for LMs to ensure that each unit operates as required by the airports. Finally, training was a LM HRM responsibility.

Table 2. The comparison of HRM activities for LMs between airport $\mathrm{X}$ and airport $\mathrm{Y}$

\begin{tabular}{lll}
\hline HRM activities of LMs & Airport X & Airport Y \\
\hline Performance management & Yes & Yes (only in large units) \\
Attitudes and disciplinary management & Yes & Yes \\
Rewards management & Yes & No \\
Work arrangement & Yes & Yes (only large units) \\
Training & Yes & Yes (only large units) \\
\hline
\end{tabular}

While there were similarities amongst participants' experience of four HRM activities to be performed by LMs, the level of involvement expected differed for these HRM activities. It was found that LMs in the Airport X were expected to have greater influence in each of the HRM activities compared to LMs in Airport Y. Table 3 shows three levels of LMs' involvement in HRM activities, classified as high involvement, low involvement and no involvement. The level of involvement was measured through LMs' participation in the HRM activities. The high involvement of LMs is described by their participation in most processes involved in the HRM activities. LMs' involvement was not limited to implementation, but also planning some HRM activities. The low involvement of LMs in HRM activities meant that they are expected to be involved in implementation, while planning activities were managed by the unit head. Moderate involvement represents a situation where LMs involve in both aspects of implementation and planning but together with the unit head. LMs will take no action without presence or approval from the unit head.

Table 3. Differences of LMs' involvement in the HRM activities

\begin{tabular}{llll}
\hline \multirow{2}{*}{ HRM activities of LMs } & \multicolumn{2}{l}{ Case study airports } & \\
& Airport X & Airport $Y$ & Large units \\
\hline Performance management & High & Low & Soll units \\
Rewards management & High & No & No \\
Attitudes and disciplinary management & High & Low & No \\
Work arrangement & High & Low & No \\
Training & High & Low & No \\
\hline
\end{tabular}

\section{Discussion}

The concept of role expectation was used to interpret the findings of the role evaluators' perceptions about LMs' HRM role. Role expectations have been defined as the demands and assessment of specific behaviors for a role that are formally written down (Biddle, 1986). The assumption has been that the role evaluators' perception would influence the design of the company's HRM policies and practices, to assist LMs in meeting the requirements of their HRM role. In understanding the allocation of work roles in the organization, role theory highlighted the importance of role evaluators' expectations because it was assumed that the role holder enacted their role based on what was expected and required by others in the role set (Katz \& Kahn, 1978). While early 
developments of role theory noted that expectations were the crucial aspect that affected the performance of the role (Biddle, 1986), this study confirmed that this remains the same in the modern organization. This was particularly true in discussing how the LMs' HRM role was defined through involvement in HRM activities, and the intended HRM role in the Malaysian airport sector amidst constant environmental changes.

In this study, the explanation of the LMs' HRM role was made in relation to their involvement in HRM activities. While most studies, such as Larsen and Brewster (2003) and Currie and Procter (2001), discussed their findings based on one single HRM activity (or several activities that were decided earlier by the researcher), this study provided understandings of LMs' HRM activities from participants' own definitions. This study reported five HRM activities of LMs perceived by role evaluators: performance management, reward management, attitudes and disciplinary management, work arrangement and training. This study captured one HRM activity that was rarely used by HR scholars, namely work arrangement. The involvement of LMs in work arrangement suggests that LMs ability in organizing employees work activities is important in aligning the unit level outcomes and organizational goals. In fact, this relationship has been proved in the previous study which found that LMs play an important part in influencing employee engagement to their work due to the close relationship between line managers and employees at the unit (Alfes, Shantz, Truss, \& Soane, 2013). The identification of LMs' HRM activities provided a good explanation of the exact HRM role of LMs, with depth and broad coverage regarding LMs' involvement in each activity. In fact, this specification was lacking in the HRM literature and contributed to unclear definitions of LMs' HRM roles.

Differences in the number of HRM activities between airports can be explained by a number of factors and in particular, the airport size made a difference. The literature reveals that organizational size is a factor that influences role expectations (Truss et al., 2002). Researchers suggest that more expectations are reported in larger organizations compared to smaller organizations. This explains why LMs in Airport X were expected to be more involved in HRM activities compared to LMs in Airports Y. As the international airport, Airport X was larger in size with more employees to be managed than Airport Y. In addition, Airport X had longer operating hours and was capable of accepting more, and larger, aircrafts per day.

A ratio of LM to employees varied between airports and units. In average, one LM at Airport X supervised around 14 employees. Airports $\mathrm{Y}$ had a ratio of 1:9 for LMs to employees at the large units, with 1:2 for the smaller units. This reflected a greater influence of LMs at Airports X than those at the other airports. They were involved in more HRM activities and specifically reward management. As LMs at Airport X were responsible for managing employee performance evaluation forms; this led them to being involved in rewards management. They were responsible for completing the performance evaluation form and made recommendations to the unit heads about rewards. LMs had to continuously monitor employee performance to assist their judgment and make the right evaluation for each and every employee under their supervision. This differed for LMs at Airports $Y$ and $\mathrm{Z}$ because the final documentation was completed mainly by the unit heads, which were held accountable for decisions on employee rewards.

In general, role evaluators perceived that LMs' involvement in HRM activities for Airports $\mathrm{Y}$ was difficult to define because their involvement was often overshadowed by the unit heads' influence. This is consistent with Regner (2003), who suggested that situations in the organizational peripheries required LMs to be more flexible and explorative, depending on the situation. The situation at the organizational peripheries was regarded as more complex and unstable compared to the organizational centre. Regner's (2003) findings effectively explain situations in these airports. For instance, as a larger airport, LMs' involvement at Airport X was defined clearly by the role evaluators. Perhaps this occurred as more employees were employed at the Airport X, which allowed the allocation of work to be made based on different functions and specialisations. Marginson et al. (1993) suggested that to reduce employees doing cross-functional tasks, a clear definition of LMs' HRM role is needed (Renwick, 2000).

As a small airport, Airports $\mathrm{Y}$ was faced with complex situations where they needed to deal with limited number of employees while maintaining standard quality services. This shaped the allocation of work among employees in the units, including the LMs' HRM role. The limited number of employees made the allocation of LMs' role dependent on the airport's needs and situation. While the size of the units differed between one another, it appeared that more expectations were required from LMs at the large unit than smaller unit. The smaller unit had less than 12 employees, while the larger unit had more than 12 employees. In the larger unit size meant more employees required management compared to the smaller size, indicating a need for more LM involvement in HRM activities. LMs in the smaller units were responsible for more operational tasks because the limited number of employees required them to oversee several operational areas and provide information about employees to the unit heads only when necessary. 
Interestingly, it was found that the increased expectations for LMs to be involved in HRM activities did not depend on the power structure at the airport. Although LMs were held accountable for the outcomes of the decisions about employee work and performance in the unit, they actually had to bear the consequences of others' decisions and not their own. This was particularly true for LMs at Airport X, as they had a high involvement in most HRM processes, while the ultimate decisions depended on the unit heads. Document analysis of LMs' job descriptions confirms this finding, as LMs were only responsible for making decisions on operationally oriented tasks.

\section{Conclusion}

Organizational size has been found to be a factor influencing HRM role expectations of LMs. This study has shown a greater HRM role expectation for LMs in the larger organization. This suggests a greater reliance on LMs' HRM role in larger organization than the smaller organization. More employees per unit in the large airport required LMs to manage more HRM activities and processes as compared to those in the small airport. For the small airport, the unit head were able to handle many HRM activities because there were a small number of employees in the units.

An important finding of this study is that the different expectations of LMs' involvement in HRM activities suggests that organizational size is an important contextual condition to be considered in developing approaches in aligning HRM strategy and organizational strategy. This alignment is important to understanding the LMs' contribution to the organizational effectiveness so that misalignment between individual performance and organizational outcomes can be avoided.

Whilst the structural differences occur between airports especially with regards to the airport size, this should reflect the development of employee job descriptions including LMs. The parent company may consider the strategic priorities that they attempt to achieve within airport and differentiate the requirement to perform the job based on different strategic priorities at the airport. This means that the development of job description may include the main priority of the airport operation so that employees have a clear view of what is expected from them. This is important to improve LMs motivation on their contribution to the airport operation through their HRM role.

In reviewing the role of LMs in various HRM activities, it can be seen that their involvement varies depending on the matter and organizational context. While one HRM activity may need LMs involvement in decision making, another may be dependent on the decisions of others such as their supervisors or the HR specialists. Organizational members' expectations change and this is a factor that contributes to variation in the LMs HRM role. The impact of these expectations seems to be critical to the way that LMs' HRM role is defined and enacted. Thus, LMs need to understand what is valuable for those who are impacted by the HRM role in the organization to guide their action. However, it is interesting to know how the changing demand of the LMs' HRM role expectations are communicated to the LMs as the role holders. In addition, the effectiveness of HRM policies and procedures should be examined as how they influence employees understanding of their role expectations that are crucial to manage their own performance.

\section{References}

Alfes, K., Shantz, A. D., Truss, C., \& Soane, E. C. (2013). The link between perceived human resource management practices, engagement and employee behaviour: A moderated mediation model. The International Journal of Human Resource Management, 24(2), 330-351. http://dx.doi.org/10.1080/ 09585192.2012.679950

Balogun, J., \& Johnson, G. (2004). Organizational restructuring and middle manager sense making. The Academy of Management Journal, 47(4), 523-549. http://dx.doi.org/10.2307/20159600

Biddle, B. J. (1986). Recent developments in role theory. Annual Reviews of Sociology, 12, 67-92. http://dx.doi. org/10.1146/annurev.so.12.080186.000435

Budhwar, P. (2000). Evaluating levels of strategic integration and devolvement of human resource management in the UK. Personnel Review, 29(2), 141-157. http://dx.doi.org/10.1108/00483480010295952

Cunningham, I., \& Hyman, J. (1995). Transforming the HRM vision into reality the role of line managers and supervisors in implementing change. Employee Relations, 17(8), 5-20. http://dx.doi.org/10.1108/014254595 10103451

Currie, G., \& Procter, S. (2001). Exploring the relationship between HR and middle managers. Human Resource Management Journal, 11(3), 53-69. http://dx.doi.org/10.1111/j.1748-8583.2001.tb00045.x 
Dierdorff, E. C., \& Morgan, F. P. (2007). Consensus in work role requirements: The influence of discrete occupational context on role expectations. Journal of Applied Psychology, 92(5), 1228-1241. http://dx.doi. org/10.1037/0021-9010.92.5.1228

Gibb, S. (2003). Line manager involvement in learning and development small beer or big deal. Employee Relations, 25(3), 281-293. http://dx.doi.org/10.1108/01425450310475865

Gratton, L., Hope-Hailey, V., Stiles, P., \& Truss, C. (1999). Linking individual performance to business strategy: The people process model. Human Resource Management, 38(1), 17-31. http://dx.doi.org/10.1002/(SICI) 1099-050X(199921)38:1<17::AID-HRM3>3.0.CO;2-A

Hall, L., \& Torrington, D. (1998). Letting go or holding on-the devolution of operational personnel activities. Human Resource Management Journal, 8(1), 41-55. http://dx.doi.org/10.1111/j.1748-8583.1998.tb00158.x

Katz, D., \& Kahn, R. L. (1978). The Social Psychology of Organizations (2nd ed.). New York: Wiley.

Kaufman, B. E. (2010). A theory of the firm's demand for HRM practices. The International Journal of Human Resource Management, 21(5), 615-636. http://dx.doi.org/10.1080/09585191003658797

Khilji, S. E., \& Wang, X. (2006). 'Intended' and 'implemented' HRM: The missing linchpin in strategic human resource management research. International Journal of Human Resource Management, 17(7), 1171-1189. http://dx.doi.org/10.1080/09585190600756384

Larsen, H. H., \& Brewster, C. (2003). Line management responsibility for HRM: What is happening in Europe? Employee Relations, 25(3), 228-244. http://dx.doi.org/10.1108/01425450310475838

Marchington, M., \& Wilkinson, A. (2002). People management and development: Human Resource Management at Work (2nd ed.). London: CIPD.

McGovern, P., Gratton, L., Hope-Hailey, V., Stiles, P., \& Truss, C. (1997). Human resource management on the line? Human Resource Management Journal, 7(4), 12-29. http://dx.doi.org/10.1111/j.1748-8583.1997. tb00286.x

Nehles, A. C., Riemsdijk, M. V., Kok, I., \& Looise, J. K. (2006). Implementing human resource management successfully: a first-line management challenge. Management Revue, 17(3), 256-273.

Purcell, J., \& Hutchinson, S. (2007). Front-line managers as agents in the HRM-performance causal chain: Theory, analysis and evidence. Human Resource Management Journal, 17(1), 3-20. http://dx.doi.org/10. $1111 / \mathrm{j} .1748-8583.2007 .00022 . \mathrm{x}$

Rees, C. J., \& Johari, H. (2010). Senior managers' perception of the HRM function during times of strategic organizational change: Case study evidence from a public sector banking institution in Malaysia. Journal of Organizational Change Management, 23(5), 517-536. http://dx.doi.org/10.1108/09534811011071261

Regner, P. (2003). Strategy creation in the periphery: Inductive versus deductive strategy making. Journal of Management Studies, 40(1), 57-82. http://dx.doi.org/10.1111/1467-6486.t01-1-00004

Renwick, D. (2000). HR-line work relations: A review, pilot case and research agenda. Employee Relations, 22(2), 179-205. http://dx.doi.org/10.1108/01425450010320805

Renwick, D. (2003). Line manager involvement in HRM: An inside view. Employee Relations, 25(3), 262-280. http://dx.doi.org/10.1108/01425450310475856

Renwick, D., \& MacNeil, C. M. (2002). Line manager involvement in careers. Career Development International, 7(6/7), 407-414. http://dx.doi.org/10.1108/13620430210449939

Rollison, D., Hook, C., Foot, M., \& Handley, J. (1996). Supervisor and manager styles in handling discipline and grievance: Part two-approaches to handling discipline and grievance. Personnel Review, 25(4), 38-55. http://dx.doi.org/10.1108/00483489610123245

Sheehan, C., \& Cooper, B. K. (2011). HRM outsourcing: The impact of organization size and HRM strategic involvement, 40(6), 742.

Sheppeck, M. A., \& Militello, J. (2000). Strategic HR configurations and organizational performance. Human Resource Management, 39(1), 5-16. http://dx.doi.org/10.1002/(SICI)1099-050X(200021)39:1<5::AID-HR $\mathrm{M} 2>3.0 . \mathrm{CO} ; 2-\mathrm{I}$

Teo, S. T. T., \& Rodwell, J. J. (2007). To be strategic in the new public sector, HR must remember its operational activities. Human Resource Management, 46(2), 265-284. http://dx.doi.org/10.1002/hrm.20160 
Truss, C., Gratton, L., Hope-Hailey, V., Stiles, P., \& Zaleska, J. (2002). Paying the piper: Choice and constraint in changing HR functional roles. Human Resource Management Journal, 12(2), 39-63. http://dx.doi.org/10. 1111/j.1748-8583.2002.tb00063.x

Ulrich, D., Younger, J., Brockbank, W., \& Ulrich, M. (2012). HR talent and the new competencies. Strategic HR Review, 11(4), 217-222. http://dx.doi.org/10.1108/14754391211234940

Valverde, M., Ryan, G., \& Soler, C. (2006). Distributing HRM responsibilities: A classification of organizations. Personnel Review, 35(6), 618-636. http://dx.doi.org/10.1108/00483480610702692

\section{Copyrights}

Copyright for this article is retained by the author(s), with first publication rights granted to the journal.

This is an open-access article distributed under the terms and conditions of the Creative Commons Attribution license (http://creativecommons.org/licenses/by/3.0/). 